\title{
LA PELÍCULA: UNA CORNUCOPIA NEOBARROCA
}

\author{
Ivonne Robles Mohs \\ A María
}

\begin{abstract}
RESUMEN
A la luz de las consideraciones de Severo Sarduy se propone que esta novela, como texto neobarroco generado por la parodia por el sentido de carnavalización, desmitifica, mediante las asimilaciones Dr. Cedeño / Don Juan / Taurus y Dra. Cedeño/ Capricornio, el orden opresivo, solar, en la convivencia privada, pública y política, y proclama el orden liberador, lunar en la convención narrativa.
\end{abstract}

\begin{abstract}
In the light of Severo Sarduy's assertions, this article suggests that a novel, as a neobaroque text generated by parody through the creation of a sense of carnival, breaks the myth - via the assimilation of Dr. Cedeño / Don Juan / Taurus and Dra. Cedeño / Capricorn- of the oppressive solar order within private, public and political life and proclaims the liberating lunar order of the narrative convention.
\end{abstract}

\section{Introducción}

\subsection{Polo Moro: productividad literaria y proliferación metaliteraria}

Polo Moro es el pseudónimo que emplea Virgilio Mora en La Película (1995). Tres textos de Mora han proliferado en una rica y fecunda metaliteratura: Cachaza en la tesis de Julieta Fonseca y Marta Rivera, Cachaza: relato novedoso en la literatura costarricense (1977) y en el libro de María Amoretti, Introducción al socio-texto, a propósito de Cachaza (1989). Dos cuentos en la tesis de Maritza Castro Salazar, La cultura popular en un texto de Virgilio Mora Rodríguez (1988), y La Película en la Memoria de Enid Salazar Córdoba, Ficcionalidad en La Película, de Virgilio Mora (1995), trabajo realizado en el "Seminario de graduación: Formas narrativas en primera persona" dirigido por Jorge Chen.

\subsection{La Película: una derivación hierática de los mitos de Don Juan y del Toro}

Por una derivación hierática se entiende aquella actualización que hipervaloriza una o varias unidades de significación de un mito. Este proceso específico de transfor- 
mación se asocia con el contexto sociocultural de donde emerge el nuevo texto. No obstante, es claro que más allá de la derivación hierática, la evolución de un mito o su deconstrucción constituye, también, un modo de apropiarse de la otra cultura, de descentrarla.

En los albores del siglo XXI, La Película asimila y parodia dos significativos mitos: Don Juan y el Toro; ambos estrechamente relacionados con el orden patriarcal, solar, que ha predominado en Occidente.

La Película, como una derivación hierática, privilegia la carnavalización de la prepotencia del varón en las relaciones de pareja; puesto que, en América Latina, el machismo pervive, aunque el hombre y la mujer alcancen un similar desarrollo económico, social y cultural, como es el caso de los doctores Cedeño, unos alienistas cubanos que residen en Estados Unidos.

Es oportuno exponer, entonces, unas breves referencias sobre los mitos mencionados, con el propósito de enriquecer las presentes reflexiones.

\title{
1.2.1. El mito de Don Juan
}

Don Juan, Don Quijote y Segismundo constituyen los tres mitos artísticos que España ha producido en la Edad Moderna. Y Don Juan es el mito moderno de más extensa y diversa universalidad; al respecto, Pérez-Rioja comenta:

\begin{abstract}
Don Juan -el legendario seductor español que, desde Tirso de Molina, en El Burlador de Sevilla y convidado de piedra (1630) ha pasado a la literatura y a la música mundial- es entre todos los grandes mitos modernos, el de más universalidad, alcanzada por su asombrosa proliferación. No se puede hablar en singular -como se habla de Don Quijote, de Fausto o de Hamlet- de Don Juan. Hay que referirse, en plural, a los Don Juanes. No es posible, por lo tanto, concretarlo a una época determinada. La pluralidad de los Don Juanes pertenece a todas y a cualquier época. Por eso, en cada país y en cada generación tiene Don Juan una concepción diferente. Se le ve bajo el influjo de climas distintos, conforme al prisma de cada observador y a través, también del ambiente o circunstancias de cada momento. No es que haya solo una multitud de Don Juanes; es que hay, además, gran diversidad de interpretaciones sobre el símbolo del seductor, encarnado en Don Juan (1962: 143-4).
\end{abstract}

Así, pues, la crítica y los comentarios han sustentado también la proliferación de este mito con las diversas y múltiples reflexiones en torno a Don Juan y al Donjuanismo; el conjunto de estas opiniones es tan rica y controversial como el personaje que las ha propiciado. Del acopio que registra Pérez-Rioja (1962: 144-7), se retienen las líneas recurrentes: El burlador de Tirso de Molina o Don Juan encarna la potencia desenfrenada del sexo que no admite diferencia entre una pescadora e Isabela, una duquesa; para Don Juan cada mujer es un espejo y el amor de cada una de ellas es un espectáculo en el que él refleja su propio triunfo; Don Juan es comparable con Zeus, ese dios disipado, incestuoso, adúltero. El Donjuanismo tiene su raíz en la inagotable vanidad masculina; es la expansión violenta de la sensualidad, que se salta las reglas impuestas a las pasiones humanas; es un monstruoso egoísmo. Pero, también, el drama de Don Juan, con su espíritu de rebeldía, pone al descubierto una crisis literaria y religiosa; es un universo sobre la condición del hombre, su dualidad, su drama de la came y el espíritu. 


\subsubsection{El mito del Toro}

Como arquetipo de cabeza de la famila patriarcal, Zeus es "creador", puesto que es "fecundador", es decir, fuerza genésica y de violencia, resortes indispensables de las energías que aseguran la fertilidad cósmica, y en cuanto tal, es un toro como en el mito de Europa (Eliade 1975: 94).

El mito de Zeus es el del que nace jefe, de quien emana todo poder y la justificación de todo autocratismo, y reviste las formas variadas del padre, del maestro, del profesor, del jefe, del patrón, del juez, del marido; pero el autocratismo es la antítesis de la autonomía, así, Zeus deviene esclavo de su propio poder (Chevalier 1995: 1036-7).

El toro es solar por el fuego de su sangre y la irradiación de su simiente; evoca el macho impetuoso y, también, el Minotauro, guardián del laberinto cretense.

La exposición, la proliferación y las interpretaciones del mito del Toro -y por consiguiente, de cada uno de sus componentes: Zeus, Europa, Minos, Pasifae, el toro de Poseidón, Dédalo, el Minotauro, el laberinto, Teseo, Ariadna y Dionisios- desbordarán los alcances de este estudio, por lo tanto, sólo se retiene que el mito de Europa -cuya representación es una matrona coronada y que lleva en sus manos un cetro y el cuerno de la abundancia- relaciona la luna y el sol, y que esta asociación reaparece en las otras significativas conjunciones: Minos y Pasifae, Pasifae y el toro, y el Laberinto, el Minotauro y Ariadna; puesto que Pasifae y Ariadna son dos de los diversos nombres de la luna (Graves: 1994: 240, 278), y Minos, el Toro, el Laberinto y el Minotauro constituyen símbolos solares.

Como su padre, Minos, el legislador sagaz o el tirano cruel, exaspera a Pasifae con sus infidelidades. Si Zeus y Hera discuten continuamente y ella lo humilla con sus intrigas, Pasifae hace que su esposo eyacule serpientes y escorpiones, cuando él comete adulterio. Empero, Teseo incumple, también, una promesa de amor.

\subsection{El horizonte de lectura}

La Película, como texto neobarroco, está constituido, generado, por el principio de parodia, por el sentido de la carnavalización. En consecuencia, desmitifica, mediante las asimilaciones Dr. Cedeño / Don Juan / Taurus y Dra. Cedeño / Capricornio, el orden opresivo, solar, en la convivencia privada, pública y política, y proclama el orden liberador, lunar, en la convención narrativa.

\subsection{Barroco y Neobarroco: una perspectiva de análisis}

De acuerdo con Severo Sarduy (1977: 167-84), lo barroco estaba destinado, desde su nacimiento, a la ambigüedad, a la difusión semántica. El enmascaramiento o la extrema artificialización practicada en muchos textos latinoamericanos, le permite al narrador cubano señalar, en estos, la instancia de lo barroco. Él distingue tres tipos de artificialización: la sustitución, la proliferación y la condensación; es decir, en el primer caso, el significante es escamoteado y reemplazado por otro; en el segundo, una cadena de significantes progresa metonímicamente y circunscribe el significante ausente; y en el último, de la fusión, del intercambio o del choque de dos de los términos de una cadena significante, surge un tercer término que resume semánticamente los dos primeros. 
Sarduy refiere que un texto, en la medida en que autoriza una lectura en filigrana, en que esconde otro texto, permite descifrar que el barroco latinoamericano participa del concepto de parodia, tal como lo definió Bajtin. Según el formalista ruso, la parodia deriva del género "serio-cómico" antiguo, el cual se relaciona con el folklor carnavalesco -de allí su mezcla de alegría y tradición- y utiliza el habla contemporánea con seriedad, pero también inventa libremente, juega con una pluralidad de tonos.

Las saturnales, las mascaradas del siglo XVI, el Satiricón, Boecio, los Misterios, Rebalais, pero, sobre todo, El Quijote, son los mejores ejemplos de carnavalización de la literatura que el barroco latinoamericano ha heredado, en términos del escritor cubano.

La carnavalización implica la parodia, en tanto que equivale a confusión y afrontamiento, a intersección de distintos estratos, de distintas texturas lingüísticas, a intertextualidad; lo barroco se presenta, pues, como un espacio de diálogo, una polifonía; como una red de conexiones, de sucesivas filigranas, cuya expresión gráfica no es lineal, bidimensional, plana, sino en volumen, espacial y dinámica. En la carnavalización del barroco se insertan, como trazos específicos, la mezcla de géneros, la intrusión de un tipo de discurso en otro -cartas en un relato, diálogo en esas cartas, etc.-.

El barroco, cornucopia rebosante, prodigalidad y derroche de toda funcionalidad, de toda sobriedad, es también la solución a la saturación verbal, a la abundancia de lo nombrante en relación con lo nombrado, a lo enumerable, al desbordamiento de las palabras sobre las cosas. Lenguaje que habla del lenguaje, la superabundancia barroca es generada por el suplemento sinonímico por el doblaje inicial, por el desbordamiento de los significantes.

Sarduy arguye que un texto es propiamente barroco en la medidad en que estos elementos -suplemento sinonímico, parodia, etc.- se encuentran situados en los puntos nodales de la estructura del discurso, o sea, que orienten su desarrollo y proliferación. De aquí que haya que distinguir entre obras en cuya superficie flotan fragmentos, unidades mínimas de parodia, como un elemento decorativo, y obras que pertenecen específicamente al género paródico y cuya estructura entera está constituidad, generada, por el principio de la parodia, por el sentido de la carnavalización.

Sarduy propone algunos elementos para una semiología del barroco latinoamericano y, para tal efecto, sigue el concepto de grama, propuesto por Julia Kristeva.

Así, para la formalización de la operación de descodificación, postula la intertextualidad y la intratextualidad.

En el primer caso, diferencia dos modos de incorporación del texto extranjero en el texto: la cita o la forma elemental del diálogo, y la reminiscencia, o el diálogo que modifica los estratos más profundos del texto receptor.

En el segundo caso, distingue los gramas fonéticos, los sémicos y los sintagmáticos. En particular, los fonéticos constituyen las otras posibles organizaciones y las otras constelaciones de sentido de las letras -además del sentido instaurado en el recorrido lineal, "normal" de la página- y de las líneas tipográficas, paralelas y regulares; ambas, las letras y las líneas ofrecen sus fonemas a otras lecturas, a quien quiera escucharlas, como en el anagrama, en el acróstico, en el bustrófedon y en todas las formas verbales o gráficas de la anamorfosis, o sea, la imagen deforme o confusa, o regular o acabada, según desde donde se le mire.

En suma, el barroco actual, el neobarroco, refleja estructuralmente la inarmonía, la ruptura de la homogeneidad, del logos en tanto que absoluto, la carencia. El neobarroco es el 
reflejo necesariamente pulverizado de un saber que sabe que ya no está "apaciblemente" cerrado sobre sí mismo. Es el arte del destronamiento y de la discusión...

\section{La Película y la carnavalización}

\subsection{La carnavalización del laberinto}

El doctor Tulio Cedeño y la doctora Cedeño laboran en el Bronx, New York, en la Clínica Central y ella en el State Hospital; además, la galena ejerce en la Clínica Salud, donde se confiesa o se desahoga con el doctor Mora quien, también, comparte unas horas por el día con el doctor Cedeño en la Clínica Central.

Los doctores Cedeño trabajan en el Bronx, pero nunca parten juntos. El médico viaja en su carro Ford, sobre la carretera, y la esposa en autobús y, fundamentalmente, en tren subterráneo, debajo de la carretera; este juego de luz-oscuridad es muy significativo, puesto que, de este modo, el texto parodia en conjunto la colosidad y la miseria de la gran ciudad de New York.

Esta ciudad, focalizada en el Bronx, es presentada como "una realidad imposible de imaginar", como "un paisaje espectral", donde reina la pobreza, la droga, la especulación de los tranquilizantes y la negligencia de los maestros, de los médicos y de los consejeros de las clínicas de rehabilitación para adictos a la heroína.

Frente a esta decadencia material y humana, la colosidad se muestra en el George Washington Bridge, una superestructura que comunica el Bronx, New York, con el Estado Jardin, New Jersey; en uno de los suburbios de este último estado, residen los doctores Cedeño. Este puente es "un caos infernal", un lugar atascado de vehículos, una realidad congestionada; por medio de la travesía que efectúa Cedeño, se muestra el perfil de Manhattan, donde un helicóptero vuela sobre las aguas oscuras y mansas del Hudson y sobre las que se desliza sereno un velero imponente.

Empero, este paisaje contemplado por los que viajan sobre la carretera es contrastado con el que frecuenta la doctora, "una telaraña de túneles oscuros y sucio", por los que miles de trenes se deslizan en todas direcciones "como reptiles locos". De la misma manera que en el autobús, el cual arranca brusca e inesperadamente y la manda al suelo, la galena vive la violencia del tren, lucha para subir entre la multitud, luego, mantiene precariamente su equilibrio, apoyada a una barra a la que agarran veinte más; cuida su cartera y cierra los ojos porque:

El ruido es ensordecedor; el chirrido de las ruedas, enervante. El crujir de los railes hace vibrar nuestros intestinos (Moro 1995:17).

En este "dédalo" del subsuelo de la ciudad habitan los roedores más grandes del mundo y parte de la población más indigente de los Estados Unidos, corre un millar de trenes con más de tres millones de newyorkinos a las cuatrocientas sesenta y nueve estaciones ubicadas en cuatro de los cinco condados que conforman la ciudad, y abundan los asaltos, los crímenes, los vicios y las perversiones sexuales.

Como es evidente, New York se une a otras ciudades y a otros tantos alrededores. De igual manera que este laberinto urbano se prolonga indefinidamente, como una perpetua 
repetición, el laberinto doméstico de los Cedeño repite cíclicamente, durante cincuenta años, la danza carnavalesca de una "muerte matrimonial".

Los doctores llevan medio siglo de bailar un "infierno matrimonial sin perder el compás" (Moro 1995: 68); cuatro divorcios y, finalmente, cinco bodas entre ellos mismos. Los galenos viven una tácita situación de equilibrio hogareño, donde la falta de consideración del esposo adúltero y la convivencia sadomasoquista de la pareja han establecido la arraigada costumbre de la diaria y acalorada discusión matutina.

Del laberinto público y privado, el relato delimita tres centros: el Bronx, la Clínica Central (y sus dobles el State Hospital, la Clínica Salud y la Clínica del Sur) y la casa de los Cedeño. Todos constituyen el sitio, el lugar del desfile del carnaval: políticos, jefes, profesionales, administrativos, pacientes, matrimonios, hombres, mujeres y niños.

La casa de los Cedeño, la Clínica Central y sus dobles replican el paisaje espectral del Bronx. La residencia de los médicos cubanos es una mansión lúgubre, silenciosa, impersonal y "sin vida", ubicada en un barrio de casas indistinguibles, ya que todas están construidas con los mismos materiales y con el mismo diseño, pintadas con los mismos colores, y poseen una cerca de arbustos con pinos muy bien recortados. La Clínica Central es enorme, ocupa una cuadra y está rodeada por una inmensa reja metálica, con pequeñas cámaras colocadas en puntos estratégicos.

De conformidad con su simbolismo, la cerca o el muro no sólo protege, defiende, separa, sino que advierte, asimismo, al no iniciado "del peligro al que se expondría penetrando allí sin las precauciones" (Eliade 1975: 331).

En este contexto, las cercas naturales o metálicas protegen o guardan a los Don Juanes, a los Toros latinoamericanos en la ciudad de New York.

\subsection{La carnavalización de Don Juan}

La Película está conformada por tres partes: una larga sección innominada de sesenta y cuatro páginas, un Epílogo y un Postcriptum.

La primera, narrada con los rasgos del discurso cinematográfico (reparto, planos de situación o plano maestro, movimiento acelerado, primeros planos, retroacción, montaje de relación, panorámicas, planos medios, movimientos de cámara, planos de figura, ángulos de cámara, tomas de cámara, acciones paralelas, escena estática, retiro de la cámara (Salazar 1995: 33-8) ), delimita tres articulaciones temporales: el primer día, el segundo y el tercero; este último, a su vez, subsume sucesos de otros días. Las tres refieren el inicio del nuevo día con los acontecimientos rutinarios: la contienda entre los cónyuges, el refugio de la doctora en la lectura del horóscopo, que realiza Alberto Mercante por la radio, y la partida hacia el trabajo o hacia los alrededores de la ciudad cuando Cedeño finge o se declara enfermo, deprimido, para preparar la celada que aparentemente acabará con su esposa.

En la pelea del primer día, la galena le reprocha al marido el nuevo adulterio y su habitual estilo de vida: exhibirse y pregonar que es irresistible, un sabelotodo y un millonario, que ha sido infeliz con ella y que por eso sólo le dio un hijo, que ella se hizo médica gracias a las conexiones de él en la facultad de medicina...

Empero, la doctora zahiere a Cedeño, ilustra la presunción del consumado mujeriego para contrastarla con su inmadurez, con su senilidad y con su deficiencia física localizada, 
precisamente, en el miembro viril. En dos oportunidades, ella recalca la incontinencia que padece su esposo; no obstante, los puntos suspensivos de la primera caracterización dejan pendiente otra u otras informaciones:

Cuándo vas a madurar, Cedeño? Cuándo vas a entender que estás viejo, que eres un viejo incontinente y ... (Moro 1995: 8).

No te da vergüenza, viejo: orinándote en los pantalones y saliendo con mujeres que podrían ser tus bisnietas? (Moro 1995: 9).

Además, le echa en cara el persistente amorío que sostiene con Evelyn, una trabajadora social, una ninfomaníaca y con daño cerebral ocasionado por las drogas y el alcohol, a quien Cedeño conoció en la Clínica del Sur.

No obstante, el médico fornica, también, con sus pacientes esquizofrénicas de la Clínica Central: Isabel, Casilda y Juana, entre otras, y de quienes abusa, manipula aprovechándose de su profesión y de las paupérrimas condiciones de vida de ellas. De estas tres últimas, el relato destaca la relación con Isabel, una joven de diecinueve años y que aparenta veinticinco, alta, bonita y muy pobre, maltratada por la vida y por las instituciones. Isabel come un poco mejor cuando el doctor le compra algunos hot dogs y un refresco; después de la precaria dádiva, Cedeño alquila un cuartucho y la somete a toda clase de degradaciones y la culpa de su impotencia. El narrador expresa:

Enfurece cuando no logra tener una erección, la emprende contra su pareja a la que culpa de su impotencia, la abofetea dos veces y la denigra con las palabras más soeces (Moro 1995: 26).

A la luz de estas líneas, la información suspendida empieza a completarse: el mujeriego es incontinente e impotente. Es la doctora quien ratifica dichas caracterizaciones y, con mordacidad, suma otra calificación: se las da de Don Juan; es decir, ella lo despoja del nombre, la individualidad, lo asimila con el estereotipo, construye, pues, una especularidad entre ambos. Especularidad que también se refuerza con la asociación Cedeño / Isabel o don Juan / Isabela, los personajes acentuados en la versión de Tirso de Molina. En los siguientes términos, la galena confiesa al doctor Mora las anomalías físicas de su esposo, las consecuentes dificultades en el encuentro sexual y hasta la perversidad de Cedeño:

\footnotetext{
Imagínate, a estas alturas incontinente y dándoselas de Don Juan. Un Don Juan impotente, Mora. Sí. Nunca me atreví a decírtelo, pero es la verdad. No imaginas los malabares que hay que hacer para que el viejo tenga una erección. El orgasmo en un dos por tres. Sin embargo, para llegar ahí hay que recorrer todo un largo viacrucis. Al viejo, toda la vida, especialmente ahora, le han encantado las cosas raras (Moro 1995: 32).
}

En el segundo día, los doctores se enfrascan en otra discusión; el motivo es Evelyn otra vez. El doctor enfurece y se encierra en el baño; a cada acusación de la esposa, él responde con un flato. En la intimidad del baño, la cámara explora a Cedeño para ofrecer otra caracterización suya, ahora como una figura de carnaval:

Aquí la cámara escruta en forma brutal al viejo: revelándonos el paso de los años: los pechos péndulos, flácidos, descansando sobre el abdomen enorme, globuloso que reposa sobre las rodillas; las piernas hinchadas, llenas de várices; las nalgas enormes con miles de estrías; el miembro diminuto (Moro 1995: 36). 
De este modo, el narrador delinea el reír carnavalesco, que brota de lo cómico y de lo trágico; en el caso particular, de la descripción de las descomunales dimensiones del cuerpo de Cedeño y de su diminuto miembro. Esta descripción se intertextualiza en los primeros elementos del realismo grotesco y se estructura con base en el gigantismo y la miniaturización.

Paródicamente, lo diminuto describe, entonces, la carencia o falta de cualidades del miembro, una deficiencia gigante en un Don Juan, sobre todo, si se tiene en cuenta que, como primera acepción del adjetivo "diminuto", el Diccionario de la Lengua Española (1992: 752) consigna:

Defectuoso, falto de lo que sirve para complemento y perfección.

Las parodias proliferan. Cedeño se confiesa con Isabel, quien no lo escucha y parece que sufre alucinaciones visuales y auditivas; a ella le confía los pormenores de su vida amorosa. En suma, el médico se convierte en paciente de la esquizofrénica; así, se caracteriza la conciencia de psiquiatra de Cedeño y su salud mental.

Como Isabel, el doctor ahora habla solo y disocia pero de manera diferente a ella, que es expulsada de la Clínica Central, o sea, la privan de su poca libertad, la esposan y la envían al State Hospital, como represalia del enfrentamiento de Cedeño con La Flaca. Esta lo increpa por fornicar con las pacientes, por arriesgar la imagen ya cuestionada de la corporación, y él le recuerda las otras corrupciones que el poder central de la institución comete con los enfermos, por ejemplo, se queda con parte de queso que el gobierno regala para ellos, con los tokens, etc. En este círculo de corrupción, Isabel es expulsada so pretexto de que no pertenece al área de la Clínica y el doctor permanece en su trabajo.

Convertido en paciente, otros enfermos se vuelven censores y caricaturizan al doctor Cedeño; se quejan de que su cubículo huele a orines y de que se duerme cuando los atiende.

Y si la transferencia con Isabel parodia la conciencia de Cedeño como alienista, con Evelyn la transferencia carnavaliza su esencia de hombre mujeriego. Evelyn, la ninfomaníaca, lo traiciona con otros, se burla, se aprovecha de su dinero y lo convence de que no soporta que la relacionen con un casado; él prepara, entonces, el homicidio de su esposa. Con Evelyn se engloban también las otras parodias; con ella, es claro que el doctor requiere de medios externos para estimularse: películas pornográficas, senos voluminosos, escabrosos negliges, altos tacones, sensual pelo largo y hasta la droga de la amante. Sin embargo, la excitación resulta deficiente; antes de empezar el acto sexual, él se duerme y ronca. Sólo se vuelve vigoroso, como en su mundo onírico, cuando al celarla y querer vengarse, la golpea, la degrada, la orina y ella disfruta de este sadismo.

En efecto, el galeno satisface su lujuria en los sueños; allí se ve propietario de "una magnífica erección", juvenil, ante la que se doblegan las mujeres; por ejemplo, endereza su virilidad en dirección de tres adolescentes al apretar un botón dorado en uno de sus testículos, o sea, controla y maneja toda la situación orgánica y sexual.

Si con Freud se recuerda que el sueño puede ser una realización de los deseos insatisfechos, una manifestación de lo reprimido, es evidente que Cedeño requiere de la siesta de rigor para sentirse pleno, pero esta plenitud es ilusoria, paródica, pues, al despertar de la acogida de Morfeo la realidad se vuelve más dolorosa. 


\subsubsection{Arturo y El Gordo: más Don Juanes}

Lo dicho hasta aquí se podría comprender como las inevitables consecuencias del estado senil o mental de Cedeño; no obstante, el relato desvanece esta posible interpretación, puesto que los sueños del galeno no solo ocurren en la Clínica Central sino que incluyen, regularmente, la presencia telefónica o corporal de Arturo en el despertar del soñador. Pero la Clínica Central y Arturo solo son metonimias, "fragmentos" de El Gordo, hombre voluminoso, narcisista, amo del sanatorio y que, como Cedeño y Arturo, es otro machista. El Donjuanismo, como un laberinto más, es un continuum interminable: Arturo y Cedeño abusan sexualmente de las pacientes, Cedeño fornica con las pacientes y con Evelyn, y El Gordo con La Flaca...

\subsection{La carnavalización del Toro, del Sol}

Arturo es uno de los hombres de confianza en el imperio de El Gordo; este último es un puertorriqueño corrupto, que con la ayuda de una "sarta de lambiscones" maneja la Clínica Central; es uno de los líderes políticos más poderosos del Bronx, fundador de una gran organización médica, de la cual dicha Clínica no es más que un grano de arena. Él explota y capitaliza la enfermedad y el dolor de los pacientes "de todos los confines de la América Latina" (Moro 1995: 19), la mayoría muy pobre y que vive del Welfare o del Social Security.

Arturo es joven, pequeño, sonriente, soltero y, como se dijo, con Cedeño manipula a las pacientes; incluso los dos frecuentan a la Rubia y Cedeño comparte con él las fotos que le toma a Isabel desnuda, en el motel, en el cuchitril, en la Clínica.

La complicidad de los compinches desborda la utilización sádica de las pacientes; ya que Arturo es incondicional de El Gordo, de la Grandota y de la Flaca, pirámide del poder de la Clínica Central y en tal condición maneja múltiples y diversas informaciones de la corporación. Por ejemplo, sabe que las consultas han bajado, que La Grandota ha solicitado por órdenes superiores que hagan grupos de ocho o doce personas juntas por sesión, la manera más rápida para aumentar los beneficios; que la prensa persigue o "anda en la caza del fundador de la corporación" y que temen el escándalo periodístico si se enteran que "un profesional de la salud mental fornica con sus pacientes esquizofrénicas" (Moro 1995: 38).

El médico y el administrativo caricaturizan, entonces, el autocratismo de la Clínica; pero también los pacientes de justicia social, no hay otra cosa más eficaz que "aprovecharse del sistema" es decir "fingirse loco" (Moro 1995: 19) y declarar a los cuatro vientos que se ven visiones o se oye a los muertos.

Dentro de los encubrimientos mutuos, Cedeño se ausenta del trabajo y, por ello, telefonea y pregunta por el regreso del doctor Mora, quien ha estado en vacaciones y a él le han recargado la consulta. Arturo responde que Mora se incorpora en ese mismo día; Cedeño le solicita, entonces, que le informe a La Grandota que tiene dificultades con el carro y aquél asiente.

Esta asociación de Cedeño y de Arturo es nuevamente paródica. Ocurre el tercer día y en el marco de la rutinaria lectura del horóscopo; en ese momento, el doctor se encuentra solo en el dormitorio, sentado en el borde de la cama, vestido con los colores solares: un traje azul de saco cruzado, camisa amarilla, la asidua corbata roja, muy ancha, con una palmera 
debajo de la que se contorsionan dos rumberas, y de seguro con su "reloj de oro macizo, un Rolex de agujas refulgentes" (Moro 1995: 24). Desde la cocina llega el mensaje de Alberto Mercante:

(...) a ti Taureano que eres fuerza, vitalidad, belleza, este mes te repara sólo dichas... (Moro 1995: 51).

Esta declamación es simultánea con el diálogo de Cedeño y de Arturo. El apelativo abarca, pues, a los receptores presentes y a El Gordo, el receptor omnipresente. Posteriormente, la doctora ingresa en la habitación y se desata la contienda rutinaria. Es importante destacar que Mercante, sólo en este caso, emplea un apelativo, en los otros usa los consabidos nombres de los signos zodiacales; además, de la lectura de este tercer día, el relato sólo registra Taurus (Taureano) y Capricornio, pero elide la información correspondiente al segundo signo por medio de los puntos suspensivos y recalca la actitud de la doctora, quien como siempre, escucha con gran atención.

Desde la lectura zodiacal del primer día, la manifestación gestual de la galena delata que ella pertenece a Capricornio; al oír la declamación de este signo, se agarra de la silla y cierra los ojos:

CA-PRI-COR-NIO: no os dejéis avasallar por gente que no vale, que no te merece. Busca tus amigos lejos de tu casa, lejos del trabajo. Descansa después de la jornada diaria. Piensa. Medita. Observa tu conducta: apréndete; trata de comprender tus actos. Escúchame Capricornio: tú puedes ser feliz. Querer es poder. Déjalos que se rían, que te humillen. No les hagas caso. Tú vales mucho más que ellos. Son estúpidos, vanidosos. Perdónalos Dios mío que no saben lo que hacen. No comprenden que tú eres un ser especial, con duende. El tiempo probará que tú tienes la razón. El tiempo te absolverá. Ya deja de ponerles la otra mejilla (Moro 1995: 12-13).

Ante tan elocuente retrato, la destinataria se pone de pie, apaga la radio, parece redimida y un "leve aire de triunfo le ilumina su cara"; de este modo, la doctora concluye la sesión radical, después de llorar desconsoladamente por la diaria discusión y de que el esposo se dirige al garaje, donde revuelca todo, aumenta el desorden y hace temblar la casa.

En este primer día, Mercante, antes de leer lo correspondiente a Capricornio, proclama lo siguiente del signo Taurus:

Tu sol está en Capricornio, tu luna es Aries. Tu número de la suerte para esta semana, el siete. Tu color, el verde limón. No hagas caso a ciertos amigos que te envidian. Tú irradias, Taurus, poder, confianza, control. No dejes que gente envidiosa se interponga en el camino. Diles que se vayan al diablo: yo no os necesito. Se independiente. Independízate, Taurus. Escúchame alma de Dios: tú puedes hacerlo todo. Ten confianza. No dejes que fuerzas veleidosas te destruyan (Moro 1995: 11-2).

En el segundo día, la doctora se horroriza cuando Mercante exclama "CÁN-CER", se tapa los oídos y apaga la radio. El doctor nuevamente se marcha y la casa vuelve a temblar.

Así las cosas, se establece una gradación y una relación entre los signos zodiacales conjugados: la lectura del primer día permite asociar indicialmente al doctor Cedeño con el signo Taurus y explica que la galena es una Capricornio; la del segundo día ratifica la enfermedad que sufre la doctora y la del tercer día califica directamente al doctor como Taureano. 
Son múltiples las diversas referencias textuales que asimilan el aspecto, los gestos y las acciones de los Cedeño con los animales correspondientes: el toro y la cabra. Las respectivas caracterizaciones se organizan con base en el gigantismo y la miniaturización.

Del doctor, se destacan las siguientes:

Es grandote, contrahecho: el hombro izquierdo más cerca del suelo que el derecho (Moro 1995: 11)

Enfurece cuando no logra tener una erección (Moro 1995: 25).

Le ganó la curiosidad a mi orgullo que ese viejo ha pisoteado toda mi vida (Moro 1995: 31).

El viejo impertérrito (...) le escarba la oreja, le muerde un seno (Moro 1995: 34).

(...) me llamaba Isabel, ponte de cuatro patas, Juana, agarrámela, cuando estaba enojado me pegaba (Moro 1995: 71).

De la doctora, se resaltan éstas:

Ella es pequeña, frágil (Moro 1995: 11).

Con pasitos cortos e inciertos deja la cocina (Moro 1995: 13).

La doctora con pasitos cortos e inciertos, camina las diez cuadras que separan su casa de la parada de autobús (Moro 1995: 35).

(...) se aleja, con pasos cortitos, después de revisar su cartera (Moro 1995: 29).

Para los propósitos de esta lectura, es preciso ahondar en la vasta expresión emblemática de los signos zodiacales atribuidos a los doctores Cedeño.

Tauro ( 21 de abril a 20 de mayo) es el segundo signo del zodiaco y se sitúa entre el equinoccio de la primavera y el solsticio de verano. Es símbolo de una gran fuerza de trabajo, de todos los instintos, principalmente, del de conservación, de la sensualidad y de una propensión exagerada a los placeres. Está gobernado por Venus y está asociado a la Tierra; es un signo hiperfemenino (Chevalier y Gheerbrant 1995: 935).

Este signo, al simbolizar el período más apto para las siembras de verano, se relaciona con el mito de Júpiter transformado en toro para seducir a Europa.

Capricornio ( 21 de diciembre a 19 de enero) es el décimo signo zodiacal y comienza en el solsticio de invierno, cuando la muerte aparente de la naturaleza corresponde a la plenitud espiritual. Este signo expresa la paciencia, la perseverancia, la prudencia, la realización y el sentido del deber. Es símbolo del final de un ciclo y, principalmente, del inicio de un ciclo nuevo. Capricornio es representado por un animal fabuloso mitad macho cabrío mitad delfín, o por una cabra, cuadrúpedo trepador. Está regido por Saturno, asociado con la sombra y la oscuridad (Chevalier y Gheerbrant 1995: 163-164).

Además, Capricornio es, también, la famosa cabra Amaltea que amamantó a Júpiter. Por ello, el padre de los dioses olímpicos la incluyó entre los doce signos zodiacales. El cuerno del toro es un instrumento solar y simboliza la potencia, pero el cuerno posee otra significación: la de la fertilidad y éste es el simbolismo del cuerno de la cabra Amaltea o de la abundancia. 
La cabra es símbolo de la nutrición y de la iniciación pero, también, de la lascivia y de la voluptuosidad por su presencia en el cortejo de Dionisos (cabras y machos cabríos, sátiros y faunos con patas de cabras, etc.).

Según Mircea Eliade (1975: 150-177), la fertilidad de los animales como la de las plantas está sometida a la luna, porque ésta controla todos los planos cósmicos regidos por la ley del devenir cíclico: las aguas, la vegetación y la fertilidad.

Eliade reagrupa las manifestaciones lunares alrededor de los siguientes temas: la fertilidad, la regeneración periódica, el tiempo y el destino, y el cambio marcado por la oposición luz-oscuridad; y pone de relieve que todos los dualismos encuentran si no su origen histórico, por lo menos, su ilustración mítica y simbólica en las fases de la luna.

Para redondear estos comentarios, es necesario señalar que la luna, como norma de los ritmos y fuente de energía de vida y de regeneración, ha tejido una verdadera red entre todos los planos cósmicos; por ello, a veces resulta difícil encontrar el centro de la red, puesto que se genera una serie de intersecciones y de correspondencias que se implican una a otras, referidas al centro del que derivan todas pero articuladas en otros casos como sistemas adyacentes: todo esto se hace patente en el conjunto luna-lluvia-fertilidad-mujer-serpiente-muerteregeneración periódica.

En el marco de todas estas valiosas observaciones, es posible establecer, entonces, las siguientes equivalencias: doctor Cedeño / Don Juan / Toro / Sol y doctora Cedeño / Cabra / Fertilidad / Luna.

Es necesario retornar, pues, a las "sandeces" de Mercante, o sea, a sus aparentes simplezas, las cuales devienen en una reveladora declamación.

El gigantismo del doctor, de Tauro, se miniaturiza y la miniaturización de la doctora, de Capricomio, se agiganta. Esta inversión se destaca en la interrelación de los solsticios con dichos signos, es decir, con la apertura de la fase ascendente del ciclo anual -Capricornio- y la apertura de la fase descendente -Tauro-.

La doctora, como la cabra dionisiaca, con su tamaño y su aparente fragilidad física y emocional, es capaz de subvertir el orden imperante: ella deviene en símbolo de la vida, del calor, de la luz y, también, de la regeneración, como es evidente en sus funciones de mujer, de esposa, de madre y de médica abnegada. Con su precaria salud, vivifica al hijo, al esposo, a los pacientes y "se entrega a todas las mujeres que sufren con el alma de una hermana" (Moro 1995: 29); quizás por ello no posee nombre propio, puesto que ella se reconoce en todas esas mujeres y éstas se reconocen en la doctora. Como Amaltea, la galena es un derroche de fertilidad y de nutrición afectiva.

Por la fecundidad de este régimen existencial, la declamación de Mercante no sólo interrelaciona y complementa a Taurus con Capricornio, y con Aries (Ariadna), sino que confronta y parodia los colores solares que suele llevar Cedeño y le adjudica el "verde limón", es decir el color del reino vegetal, del agua, de la mutación y de la regeneración. Esta atribución del pitoniso se refuerza, aún más, si se atiende el propio nombre del doctor Cedeño, Tulio, el cual contiene el color verde, según lo referido por el Diccionario de la Lengua Española (1992: 2037):

Tulio (Del lat. Thule, región hiperbórea de Europa). m. Quím. Metal del grupo de las tierras raras. Es bastante denso y sus sales tienen color verde grisáseo. Núm. atómico 69. Símb.:Tm. 
Mercante reitera la asociación de la galena con las fuerzas de la naturaleza, al exclamar que ella posee "duende". El labrar los metales constituye uno de los principales oficios de los duendes (Pérez-Rioja 1962: 153-4); los metales se asimilan con la energía cósmica, con la libido, con la transmutación, con la iniciación, con la sublimación de los deseos sexuales y con la integración en una existencia equilibrida (Chevalier y Gheerbrant 1995: 628-9).

En este marco, al tener presente que el número cinco es signo de unión, de armonía y de equilibrio, número nupcial a decir de los pitagóricos, los cinco matrimonios entre los Cedeño podrían interpretarse como las oportunidades de transformación, de iniciación y, por lo tanto, de integración en una existencia equilibrada que la doctora, el duende, ofrece a Tulio, su marido. No obstante, Tulio Cedeño rehúsa la transmutación, la individualización, y continúa en el desequilibrado y desmesurado laberinto del estereotipo: Don Juan, el Toro.

Así las cosas, Mercante recomienda a Cedeño el siete como la cifra de su suerte, o sea, el número de los períodos lunares y símbolo de un ciclo, del paso de lo conocido a lo desconocido.

Cedeño muere por impacto, como él impacta y mata a la doctora, al hacerle creer que se ha suicidado, precisamente, en el ciclo de los últimos siete años de la unión matrimonial, de la enfermedad de la esposa y de su decisión premeditada de eliminarla, para que nadie ni nada obstaculice su amorío con Evelyn. Y cuando, más que nunca, exhibe su yugo carnal, actitud que se puede asociar con el número 69 del peso atómico del Tulio, por la fuerte carga libidinosa que se le atribuyen a las posiciones corporales simbolizadas en estas cifras. No es casual, entonces, que el 69 forme parte de la serie numérica del teléfono de Evelyn: "9694442" (Moro 1995: 31); y que el propio símbolo del metal, Tm, se pueda asociar con Tulio, el doctor, y Mercante o con Tulio y Mora, dadas las funciones que cumplen el pitoniso y el doctor Mora.

Después de perpetrar el homicidio, Cedeño corre veloz al apartamento de Evelyn para "darle la sorpresa de su vida"; empero, es él quien resulta sorprendido, vive la sorpresa de su vida y con horror constata la sospecha, la burla: descubre a Evelyn con su amante y muere, le explota la cabeza.

Pero la galena, la luna, muere-renace-muere permanentemente; es inagotable en su propia regeneración. Si primero fallece, en la larga sección, luego, en el Epílogo, está viva y descuenta los días de la etapa final de su enfermedad, y, por último, en el Poscriptum vuelve a expirar:

(...) dejando al marido atrás, amarrado a una silla de ruedas (Moro 1995: 72).

Por el contrario, el doctor muere y sigue simbólicamente muerto en el Epílogo y en el Poscriptum; en el primero, la galena manifiesta que su esposo, al someterse a una prostatectomía "salió descerebrado por un error del anestesista" (Moro 1995: 66), que se convirtió en vegetal y permanece conectado a un respiradero; en el segundo, el doctor es un inválido mental, un demente.

Las parodias son elocuentes: Cedeño es un Don Juan, un Toro, estéril y demente, atado a una silla de ruedas, calificación última que caricaturiza todo el simbolismo de autoridad y de soberanía de la silla y, sobre todo, del Toro.

La galena amarra, teje, como la araña. Tejer significa predestinar y, también, crear, hacer salir de su propia sustancia, igual como lo hace la araña que construye su tela de sí 
misma. El destino, hilo de la vida, es un período más o menos largo; así, a lo largo de cincuenta años y de cinco nupcias, la doctora, el duende, trata de forjar otra existencia, otro destino, para Tulio Cedeño y él se rehúsa; pero, aún así, en el período de mayor decadencia física y espiritual del galeno, ella, la luna, continúa iluminándolo: se convierte "en el guardián del doctor" (Moro 1995: 72), porque, en definitiva, él es, también, un alma de Dios, como expresa Mercante.

La Película parodia los antagonismos y como texto carnavalesco, neobarroco, constituye, a la manera del orden lunar, la reunión de los contrarios o, mejor aún, la reunión de las oposiciones no-excluyentes, como lo son el hombre y la mujer. Reunión contenida en el propio signo Tauro, por todas sus asociaciones con lo masculino y su ineludible condición de signo hiperfemenino, regido por Venus, por el amor, por la armonía.

El encuentro del hombre y de la mujer se manifiesta en la comunicación afectiva que establecen la doctora Cedeño y el doctor Mora. La galena, como Amaltea, nutre e inicia a Mora en el conocimiento de su laberinto privado, matrimonial, con lo cual fertiliza simultáneamente la labor creativa, la ficción del colega, quien refiere:

Me había sentado a escribir mi ficción a la luz de los problemas que comportaba la doctora con su marido, hacía más de un año (Moro 1995: 66).

Asimismo, el doctor Mora inicia a la doctora en el conocimiento del laberinto público y político de la Clínica Central y en el proceso creativo, puesto que ella informa, lee y hasta interpreta la ficción del médico como una tragedia, como un relato contado como una película:

Cómo se te ocurrió toda esa tragedia? (...). Me estoy poniendo más trágico que tú en tu historia. Me gusta, Mora. Y la treta que usas de contarlo todo como si se tratara de una película, es muy ingeniosa (Moro 1995: 67).

Y, además, corrige y reescribe el texto:

Desde que le había llevado el draft de mi ficción para que me diera su opinión y por qué no, con la esperanza de obtener más material para mi historia, la doctora parecía entretenerse enormemente, sugiriendo cambios aquí, la abolición de un término allá, corrigiendo la puntuación (Moro 1995: 65).

La ceremonia de iniciación de ambos ocurre en la Clínica Salud, puesto que es allí donde la doctora informa y el doctor empieza a "escribir con frenesî". Allí los médicos devienen escritores y allí inician, fundamentalmente, su liberación, es decir, su revancha contra la opresión de los Don Juanes, de los Toros, del Sol.

La doctora Cedeño es la única psiquiatra de los veinticinco que laboran en esta Clínica, pero tampoco el texto menciona otra en alguna de las otras clínicas. Esto es muy significativo, porque el aparente caso de marginalidad femenina no es más que otra parodia, un rebajamiento del poder del número, de la cantidad. El doctor Mora con la única colega denuncian juntos el sistema, toda la alienación de la que ellos no son ajenos como individuos, profesionales y empleados; mas, dicha alienación no transforma sus conciencias, no los hace ajenos a su condición de alienistas, de escritores y de seres humanos. A diferencia de la Ariadna clásica que recibe el hilo de Dédalo, la Ariadna textual, la doctora, junto con Mora 
(Dédalo) construyen el hilo, la escritura, la cual denuncia el Laberinto, los libera de los Toros y evoca la presencia de Dionisos.

Al tenor de estas líneas, es oportuno destacar con Chevalier y Gheerbrant (1995: 872879) que la serpiente, la luna, emblema de la medicina y de la salud, se asocia también con la música, con la poesía y con la adivinación; y, a la vez, se relaciona con Apolo, pero, sobre todo, con Dionisos.

Dionisos es el gran liberador, así, los éxtasis colectivos, los trances, surgen como una revancha de la naturaleza contra la ley, hija de la razón, de la opresión. En concordancia, el culto dionisiaco coincide con la perfección literaria griega. En este contexto, los autores mencionados encuentran un simbolismo de la serpiente rehabilitada en las proclamas de liberación del Romanticismo, del Surrealismo y del Psicoanálisis; a las que, evidentemente se suma La Película, que como una proclama de liberación, interrelaciona la medicina (el alienismo), la creación literaria, la adivinación y la música.

\subsection{La carnavalización del relato: un modo de concluir}

La Película, como texto neobarroco, dionisiaco, se libera de los procedimientos y de las convenciones del relato. Entrona la ambigüedad, el diálogo, la intertextualidad, la polifonía, el doble, el carnaval, el orden lunar.

La ruptura de la homogeneidad narrativa se explica en la parodia de la más elemental distribución estructural: principios, medio y fin; ya que la sucesión diegética es reemplazada por la repetición, por las conexiones en filigrana, por los puntos suspensivos; en total, la larga sección innominada, el Epílogo y el Postcriptum constituyen un laberinto sin centro.

Los personajes aparecen y desaparecen, viven, mueren y viven; dicen y desdicen; son víctimas de la vida y de la sociedad de consumo y hedonista pero también son victimarios; conocen y desconocen; generan una compleja y rica red de focalizaciones, de discursos indirectos libres y de apariciones contradictorias del universo narrado.

La ubicuidad del narrador, que conjuga la instancia personal yo-nosotros y la apersonal él, se oculta, se manifiesta, se prolifera en el empleo de los rasgos cinematográficos. No obstante, todo es un relato: si, en un primer momento, el narrador califica la cámara "como milagro" (Moro 1995: 7); luego, la galena, la lectora, determina la película, en tanto modo de contar, como una "treta", es decir, un artificio o un engaño.

Así pues, el propio título del libro, La Película, deviene en otras tretas, en una máscara que oculta, a la vez, la innominada larga sección de sesenta y cuatro páginas, narrada como una película y, por qué no a la doctora, a la peluca, quien no amaina su carácter ante las dificultades del cáncer glandular y resuelve o enmascara su calvicie post-quimioterapia con el uso de una peluca. En atención al Diccionario de la Real Academia (1992: 1564), "peluca" refiere tanto la caballera postiza como la persona que la porta:

Peluca. f. Cabellera postiza // 1. fig. y fam. Persona que la lleva o la usa.

La anamorfosis La Película / La peluca configura, entonces, una parodia. 
Esta anamorfosis La Película / La peluca, enlazadas por la " $i$ " (La Película (í) La peluca), parodia, finalmente, el autocratismo de la ficcionalidad o de la realidad en la literatura y privilegia la ambigüedad: al inicio del texto, el narrador-personaje asocia una película con su ficción, es decir, destaca la ficcionalidad en su ficción:

El otro día vi una película inolvidable. Está basada en una ficción y abre con la misma escena con que se inicia ésta (Moro 1995: 7);

al final, relaciona a la doctora, la peluca, con su ficción: niega el papel de la galena como lectora-reescritora, empero no niega el papel que ella desempeña como informante de su ficción:

(...) expiró dejando al marido atrás amarrado a una silla de ruedas y a mí con esta ficción de cuya existencia ella nunca se enteró (Moro 1995: 72).

Coexisten, entonces, las dos focalizaciones, la de la "película inolvidable" y la de la peluca inolvidable, pero, también, cada una "expiró" y, sin embargo, ambas siguen vivas en el proceso de construcción y de deconstrucción de la escritura, un orden lunar...

Todo es permutación, renovación. El lector actúa, juega y, como el texto, se renueva a cada instante.

El lector iniciado en la primera edición de 1991 y en la reedición de 1995 despeja y ríe con la sátira en el pseudónimo empleado por el autor, Polo Moro, anamorfosis de las líneas tipográficas, paralelas y regulares: La Película / Virgilio A. Mora, lo cual invierte, también, el orden en la disposición de la autoría y del título del libro: Polo Moro / La Película, borra la posible asimilación entre el doctor Mora, el narrador-personaje, y el autor, y prolifera la ambigüedad.

Además, han desaparecido el color amarillo del título como el azul del espacio que lo soportaba (Salazar 1995:18); ahora, se privilegia el pastel del pintor Miguel Hernández Bastos a quien el autor dedica el libro, y el nombre del autor y del libro aparecen en color rojizo, integrados en el color predominante de la pintura, es decir, un color cabrío.

El pastel prolifera la carnavalización, al evocar el cortejo de Dionisios, un derroche de música, de carcajada, de embriaguez y de transgresión.

$\mathrm{Y}$ entre este cortejo y el resto de los pasajeros, destacan dos personas: un hombre y una mujer que portan sendas maletas, la de ella es mucho más grande. Al hombre, que viste camisa amarilla, viaja de pie cerca de la policía, se apoya con inquietud en una barra y sostiene su maletín con precaución, le roban algo, posiblemente la billetera; la mujer, de quien sólo se destacan sus contorneadas y cabrías piernas y botas, viaja plácidamente sentada, cerca de los músicos, con la pierna izquierda cruzada sobre la derecha y despreocupada de la maleta que ha colocado a su diestra. Con estas dos imágenes asimilables a los doctores Cedeño, el pastel yuxtapone, acentúa la parodia de los antagonismos y, así, instala a Tulio Cedeño / Don Juan / Toro / Sol en el tren subterráneo, entre los túneles, destronado de su Ford, asaltado de su orden e inicado en el orden lunar.

La Película es cornucopia rebosante. 


\section{Bibliografía}

Amoretti, María. 1983. "Cachaza: el relajo del carnaval y el diálogo de los contrarios". Káñina, Revista de Artes y Letras de la Universidad de Costa Rica. VII, (4).

Cros, Edmond. 1995. "Introducción". Historia de la vida del Buscón Ejemplo de Tacaños. Madrid: Ediciones Taurus.

Chevalier, Jean y Alain Gheerbran. 1995. Dictionnaire des symboles. París: Editions Robert Laffont / Jupiter.

Eliade, Mircea. 1975. Tratado de historia de las religiones. México: Ediciones Era.

Fernández Moreno, César. 1977. América Latina en su literatura. México: Siglo XXI Editores.

Graves, Robert. 1993. Les mythes Grecs. París: Librairie Fayard.

Kristeva, Julia. 1981. El texto de la novela. España: Ediciones Lumen.

Laffite, J.P. y otros. 1995. Prépas scientifiques La Ville. París: Vubert Supérieur.

Moro, Polo. 1995. La Película. Miami, Florida: Ediciones Universal.

Pérez-Rioja, J.A. 1992. Diccionario de la Lengua Española. Tomos I y II. Madrid: Editorial Espasa-Calpe.

Salazar Córdoba, Enid. 1995. La ficcionalidad en La Película, de Virgilio Mora. Universidad de Costa Rica, Tesis de Licenciatura.

Sarduy, Severo. 1977. "El barroco y el neobarroco". En: Fernández Moreno, 167-8. 